\title{
THE HEALTHCARE MODELS: GLOBAL BACKGROUND AND UKRAINE'S DEVELOPMENT
}

\section{Lisovska Olha ${ }^{1}$}

DOI: https://doi.org/10.30525/978-9934-571-89-3_133

The healthcare pattern is a key component to influence the formation and development of the whole healthcare system in a country. Each country has made its own system of the health care that reflects historical and economic changes, cultural differences, political and social environment, the evolution of civilization and the progressive globalization. However, all of them are merely consigned to basic funding models for the healthcare system.

Around the world, they used to distinguish several basic models of funding the healthcare system: the Bismarck Model (or German model); the Beveridge Model (or English model); the National Health Insurance Model; the Out-of-Pocket Model; the Private Insurance Model; the Semashko Model (or the Soviet model).

The world's first healthcare model became the Bismarck Model. Founded in the end of XIX century it was named for German politician, Otto von Bismarck. The model is based on mandatory social health insurance. Medical care is financed partly by ring-fenced contributions from employers and partly by the employees. A distinctive feature of the Bismarck Model are the private insurance funds controlled by state or private insurance companies and heavily regulated by the

\footnotetext{
${ }^{1}$ University of State Fiscal Service of Ukraine, Ukraine
} 
government [3, p. 128]. This model has been adopted for the healthcare systems of Austria, the Benelux countries, France, Germany, Italy, Japan, Sweden, Switzerland $[1 ; 3$, p. 128].

The Beveridge Model is a healthcare system that emerged in Great Britain in 1948. It was named after William Henry Beveridge, the British economist and politician. Specific characteristics of the Beveridge is its universal health care coverage for all citizens, which is state-funded from general and regional taxation. The decision on the total amount of funding is made in the process of planning the total government spending for the country [3, p. 127-128]. This model has been adopted for the healthcare systems of Cuba, Denmark, Great Britain, Ireland, New Zealand, Spain $[1 ; 3$, p. 127].

The National Health Insurance Model combines some aspects of both the Bismarck and Beveridge models. As in the Bismarck model, the providers - that is, insurance companies - are private and, as in the Beveridge model, the government finances healthcare through tax revenue. The balance between private practice and government regulation helps to cut the costs associated with the administration of health insurance [5, p. 84]. Classic model of the National Health Insurance is applied in Canada, yet some other countries, for example South Korea and Taiwan, has adopted it as well [1].

The Out-of-Pocket Model is prevalent in poor countries where the gap between the rich and poor is substantial. Due to the lack of resources to provide mass medical care, the patients have to pay for medical service out-of-pocket. This model differs in that the rich have the access to medical care while the poor stay sick or die [5, p. 84]. Examples of the Out-of-Pocket Model include rural regions of Africa, China, India, South America [1].

The Private Insurance Model is typical to the United States of America. The healthcare is based on two main government programs - Medicare and Medicaid. Patients themselves pay for medical services and get later payments from the insurance company or reimburse the insurance value of treatment directly to the medical institution. This model is considered the most efficient in the world [3, p. 128].

The Semashko Model refers to the Soviet pattern of the healthcare founded by a doctor (physician), Mykola Oleksandrovych Semashko, after the October Revolution in 1917. This system functioned through the centralized five-year development planning. Medical care was funded through the government spending. The Semashko Model granted a universal access to free medical care, where all citizens had a right for medical treatment [2, p. 2].

Ukraine, as the other former republics of the USSR, has the Semashko Model. In due time, the Soviet model was a progressive pattern, yet it is gradually passing away nowadays. Today, Ukraine is in transition to the social insurance model that is going to be the closest to the Beveridge Model, implementing the concept of "money follow a patient". The idea of the concept is to pay health institutions for the treatment served out of the state budget, through the National Health Service of Ukraine, instead of the estimated spending for hospitals, doctors and inpatient beds, as it was with the Soviet model [4]. 
Summing up, we may argue that given the variety of funding models for the healthcare system, there is no universal model that fits all countries. It is essential for the model to be efficient and meet the needs of the patients. The social insurance model implementation is one of the priorities of medical reform, which contributes to the development of modern Ukraine. In the process of reforming Ukrainian healthcare and constructing its efficient system, it is suggested to adopt international experience and adapt to Ukrainian environment.

\section{References:}

1. Chung, M. (2017, December 2). Health care reform: learning from other major health care systems. Princeton Public Health Review. Retrieved from: https://pphr.princeton.edu/2017/12/02/ unhealthy-health-care-a-cursory-overview-of-major-health-care-systems/ (accessed March 26, 2019).

2. Jakovljevic, M., Camilleri, C., Rancic, N., Grima, S., Jurisevic, M., Grech, K., \& Buttigieg, S. C. (2018, August 6). Cold War Legacy in Public and Private Health Spending in Europe. Frontiers in Public Health, vol. 6, article 215, pp. 1-11. doi: 10.3389/fpubh.2018.00215.

3. Kulesher, R., \& Forrestal, E. (2014). International models of health systems financing. Journal of Hospital Administration, vol. 3, no. 4, pp. 127-139. doi: http://dx.doi.org/10.5430/ jha.v3n4p127.

4. Ukraine Crisis Media Center. (2017, September 11). What do you need to know about the healthcare reform in Ukraine? Retrieved from: http://uacrisis.org/60230-need-know-healthcarereform-ukraine (accessed March 26, 2019).

5. Wallace, L. S. (2013). A View of Health Care Around the World. The Annals of Family Medicine, vol. 11, no. 1, p. 84. doi: 10.1370/afm.1484. 